\title{
IMPROVED COMPUTING PERFORMANCE FOR Listing Combinatorial AlgorithMS USING MulTi-Processing MPI AND THREAD LIBRARY
}

\author{
Nguyen Dinh Lau \\ University of Education and Science, University of Danang, Vietnam
}

\begin{abstract}
This study builds up two parallel algorithms to improve computing performance for two listing binary and listing permutation algorithms. The problems are extremely interesting and practically applicable in many fields in our daily life. To parallel execution, we divide the data set input and allocate them to the processors. The article focuses on (i) the analysis of the research situation of the related works to compare and evaluate the existing problems of previous works, (ii) the analysis of the input data structure to divide data for the sub processors, (iii) the construction of parallel algorithms - proof of correctness and analysis of computing complexity, and (iv) experiments in multi-processing MPI and Thread library. Then the comparison of the results of the parallel algorithm with the sequential algorithm and the comparison of the execution time on different sub processors is discussed.
\end{abstract}

\section{KEYWORD}

Parallel algorithms, listing binary, listing permutation, bounded sequences, substituend, inversion

\section{INTRODUCTION}

Listing binary and permutation are amazing and appealing problems in discrete mathematics with numerous wide applicability. However, when the input data is large, the listing time is highly long. For example, with input $n=20$, the number of binary array is $2^{20}$. Therefore, It is crucial to build up parallel algorithms to improve the computing performance for this problem.

In Vietnam, Hoang Chi Thanh has done some Research on combinatorial [3], [4], [5], [6] , [7].

In the world, there are many researchers publishing works related to the field of combinatorial [8], [9], [10], [11], [12], [13], [14], [15], [16], [17], [18] ].

In the article [1] by Nguyen Dinh Lau, a parallel algorithm for listing permutation has been developed, but not yet applied to multi-processing MPI and Thread library. Thus, this paper is inspired by some parts of [1] to rebuild the listing permutation algorithm.

However, in [8], [9], [10], [11], the listing binary sequences algorithm is not improved to cut down on the computing performance. Particularly [3] study by Hoang Chi Thanh focuses on building algorithm based on inversion vector and bounded sequence. However, Hoang Chi Thanh has neither analyzed and proved the complexity of the parallel algorithm, nor experimented in multi-processing MPI and Thread library to compare the processing time between different processors and different data sets.

DOI: $10.5121 /$ ijcsit.2018.10504 
Therefore, this article has the following new cutting-edge points:

1. Building up a new parallel listing n-binary algorithm to improve computing performance. It deals with the analysis, and proof of the complexity and experiments in the MPI to the examine and compare computing time.

2. Basing on [1] to build up parallel listing permutation algorithm. It involves the analysis, proof the complexity and experiments in in the Thread to analyze and compare computing time.

\section{Listing Binary Sequence Algorithm}

\subsection{Sequential algorithm}

Let $\mathrm{n} \square \mathrm{N}$. List all binary sequences with $n$ length, i.e., sequence $\left[\mathrm{b}_{1}, \ldots, \mathrm{b}_{\mathrm{n}}\right]$, where $\mathrm{b}_{\mathrm{i}} \mathrm{b}_{\mathrm{i}} \square\{0,1\}$ $\mathrm{i}=1, \ldots, \mathrm{n}$.

The number of binary sequences is $2^{\mathrm{n}}$ and the first sequence $\mathrm{s}=[0,0, \ldots, 0]$. For example, given $\mathrm{n}$ $=3$, we have the 8 following binary sequences: 000, 001, 010, 011, 100,101, 110, 111

\section{Algorithm 1. Creating a sequential binary sequence with $\boldsymbol{n}$ length}

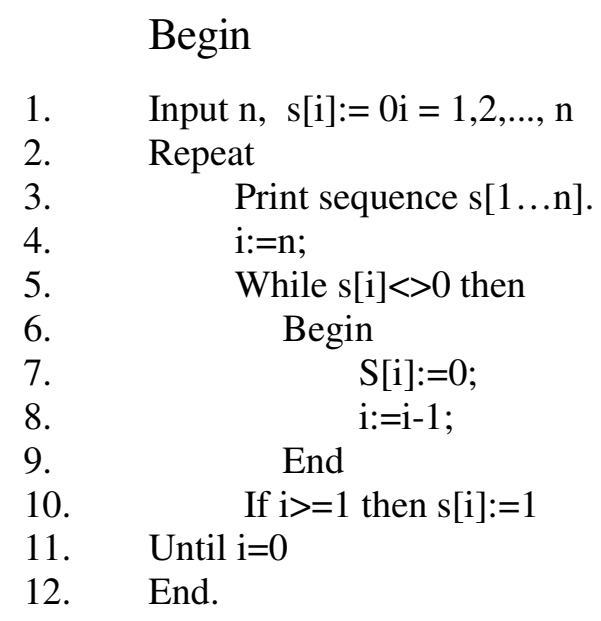

Assume s[i] in line 2 has the complexity $\mathrm{O}(\mathrm{n})$. Lines from 3 to 12 represents $2^{\mathrm{n}}$ binary sequences. So the complexity of the algorithm is $\mathrm{O}\left(2^{\mathrm{n}}\right)$.

\subsection{Parallel Algorithms}

Sequential algorithms might take a long time to process if $n$ length is large. Therefore, it is necessary to build parallel algorithms to improve computing performance for the algorithms.

This newly-built parallel algorithms use $k$ processors $\left(\mathrm{R}_{0}, \mathrm{R}_{1}, \ldots, \mathrm{R}_{\mathrm{k}-1}\right)$ with $\mathrm{k}=2^{\mathrm{n}^{\prime}}+1$, where $\mathrm{n}^{\prime}=$ $0,1, \ldots, n-1$. The processor $R_{i}$ receives the output value which is the input value of $R_{i+1}(i=1,2$, $\ldots, \mathrm{k}-2)$. Note that the $\mathrm{R}_{0}$ main processor neither participates in the computation process nor lists binary sequences. $\mathrm{R}_{0}$ only sends and receives information. 
The input on the processors is illustrated as follows:

Let $\mathrm{n}$ be the input value, list all binary sequences, let $\mathrm{n}$ ', then we have the number of $k$ processors. Then run the sequential algorithm (Algorithm 1) to list the binary sequence of $n^{\prime}$ length. After adding the bits 0 on the right, the binary sequence of $n^{\prime}$ length has a sufficiently long binary sequence of $n$ length will be divided by the processor $\mathrm{R}_{0}$ for the additional processors $\left(\mathrm{R}_{1}, \mathrm{R}_{2} \ldots\right.$ $\mathrm{R}_{\mathrm{k}-1}$ ) as the input value.

For example, given $n=4, n^{\prime}=2$. Then, the number of processors $k=5\left(R_{0}, R_{1}, \ldots, R_{4}\right)$

The binary sequence $\mathrm{n}=4$ is: $0000,0001,0010,0011,0100,0101,0110,0111,1000,1001$, $1010,1011,1100,1101,1110,1111$

The binary sequence $n{ }^{\prime}=2$ is: $00,01,10,11$. Then, the sequences $0000,0100,1000,1100$ are the input of four su processors $\left(\mathrm{R}_{1}, \mathrm{R}_{2}, \mathrm{R}_{3}, \mathrm{R}_{4}\right)$.

The finishing condition of the four processors $\left(R_{1}, R_{2}, R_{3}, R_{4}\right)$ is $0100,1000,1100,1111$.

$\mathrm{R}_{1}$ listing binary: 0000, 0001, 0010, 0011

R2 listing binary: 0100, 0101, 0110, 0111

R3: listing binary 1000, 1001, 1010, 1011

R4: listing binary $1100,1101,1110,1111$

The following is the parallel algorithm

\section{Algorithm 2. Creating a parallel binary sequence}

1. Begin

2. Input $\mathrm{n}, \mathrm{n}$ '

3. $\mathrm{k}:=2^{\mathrm{n}}+1$

4. If Rank=0 then // main processor $\mathrm{R}_{0}$

5. Begin

6. Call Algorithm 1 (n') // listing binary sequence $\left(\mathrm{t}_{1}, \mathrm{t}_{2}, \ldots \mathrm{t}_{\mathrm{n}^{\prime}}\right)_{\mathrm{i}} \forall \mathrm{i} \in 1, \ldots, 2^{n^{\prime}}$ of length $\mathrm{n}^{\prime}$

7. Create $2^{n^{\prime}}\left(t_{1}, t_{2}, \ldots t_{n^{\prime}}, t_{n^{\prime}+1}, \ldots, t_{n}\right)_{i}:=\left(t_{1}, t_{2}, \ldots t_{n^{\prime}}\right)_{i} \cup(0, \ldots, 0)_{i} \forall i \in 1, \ldots, 2^{n^{\prime}}$ of length $n$ n-n'element

8. Send $\left(\mathrm{t}_{1}, \mathrm{t}_{2}, \ldots \mathrm{t}_{\mathrm{n}^{\prime}}, \mathrm{t}_{\mathrm{n}^{\prime}+1}, \ldots, \mathrm{t}_{\mathrm{n}}\right)_{\mathrm{i}} \forall \mathrm{i} \in 1, \ldots, 2^{n^{\prime}}$ to $2^{\mathrm{n}^{\prime}}\left(\mathrm{P}_{1}, \ldots, \mathrm{P}_{\mathrm{k}-1}\right)$ sub processors

9. $\quad$ End

10. For $\mathrm{i}:=1$ to $\mathrm{k}-1$ do

11. Begin

12. Listing binary sequences in the corresponding processor segment

13. Send the result to $\mathrm{R}_{0}$

14. End;

15. $\mathrm{R}_{0}$ print results

16. End.

Let $2^{\mathrm{n}}=2^{\mathrm{n}^{\prime}}+2^{\mathrm{n}-\mathrm{n}^{\prime}}$ where $2^{\mathrm{n}^{\prime}}=\mathrm{k}-1\left(\mathrm{R}_{1}, \mathrm{R}_{2}, \ldots, \mathrm{R}_{\mathrm{k}-1}\right)$, then if $\mathrm{R}_{1}$ initiates a binary sequence with a value 0 and $n^{\prime}$ length is $0 \ldots 000, \mathrm{R}_{2}$ initiates binary sequence with a value 1 and $n^{\prime}$ length is $0 \ldots$ $001, \mathrm{R}_{3}$ initiates binary sequence with $n^{\prime}$ length is $0 \ldots 010, \mathrm{R}_{4}$ with $n^{\prime}$ length' is $0 \ldots 011$, 
Continue to $\mathrm{R}_{\mathrm{k}-1}$. Each processor $\mathrm{R}_{1}$ to $\mathrm{R}_{\mathrm{k}-1}$ connects the $2^{\mathrm{n}-\mathrm{n}^{\prime}}$ binary sequence has $n-n^{\prime}$ length to left of the sequence. Send the results to processor $R_{0}$. $R_{0}$ prints results and ends.

Example 2: Given $n=4, n^{\prime}=2$, then $k=5$, then $R_{1}$ holds $00, R_{2}$ holds $01, R_{3}$ holds $10, R_{4}$ holds 11 .

$\mathrm{R}_{0}$ lists $2^{\mathrm{n}-\mathrm{n}^{\prime}}=24-2=4$ binary sequences with the length $\mathrm{n}-\mathrm{n}^{\prime}=4-2=2: 00,01,10,11$. Then broadcast $00,01,10,11$ to sub processors. The processors $\mathrm{R}_{1}, \mathrm{R}_{2}, \mathrm{R}_{3}, \mathrm{R}_{4}$ receive data from the Broadcast command, Then connect the sequence 00 to the left of the sequences in $R_{1}$, then $R_{1}$ shows: 0000, 0001, 0010, 0011. $\mathrm{R}_{2}$ represents: 0100, 0101, 0110, 0111. $\mathrm{R}_{3}$ shows: 1000,1001 , $1010,1011 . \mathrm{R}_{4}$ represents: $1100,1101,1110,1111$

Algorithm 2 is rewritten as algorithm 3 as follows:

\section{Algorithm 3. Creating a parallel binary sequence by data Broadcast}

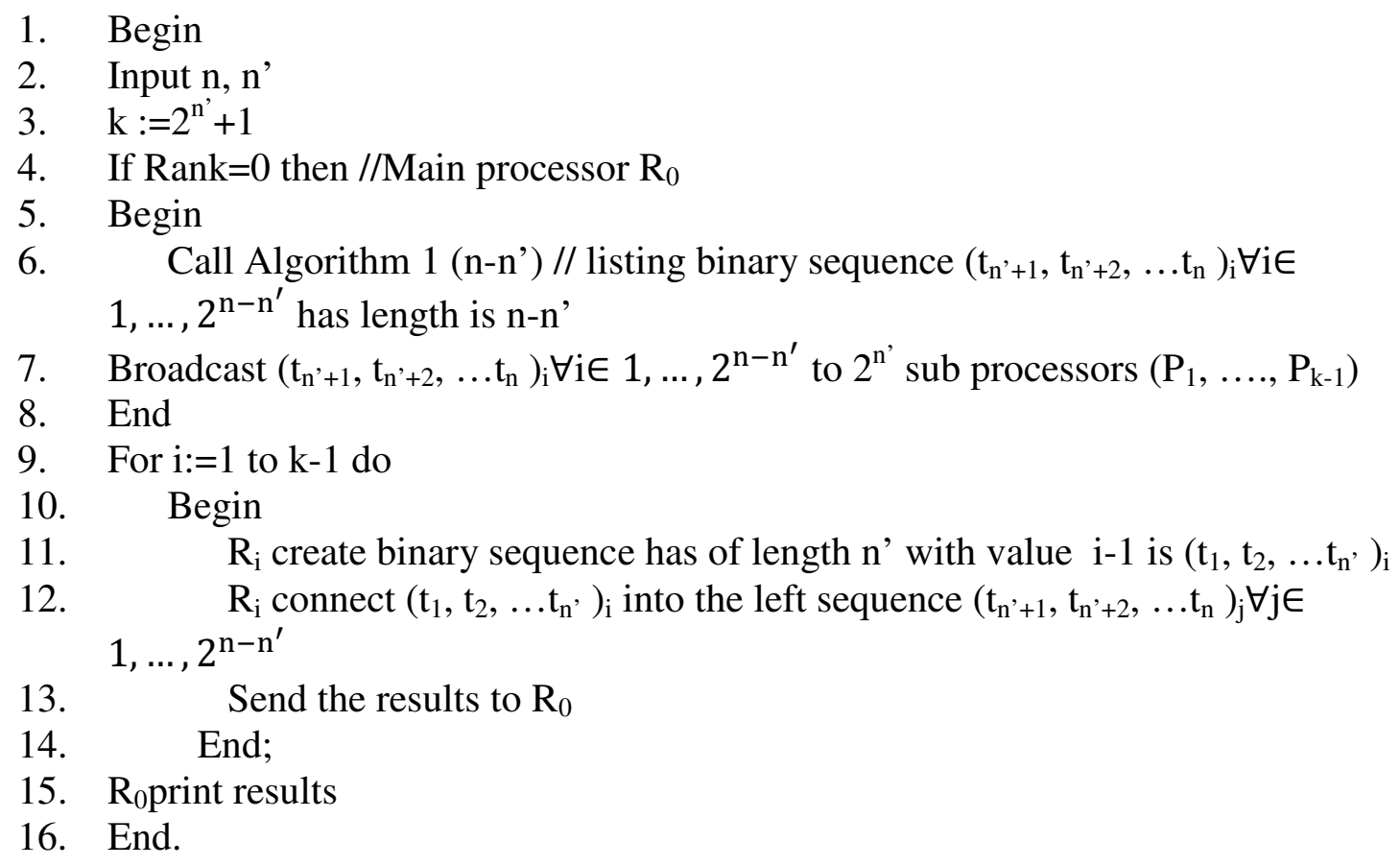

\subsection{EXPERIMENTAL RESUltS}

The world of parallel multiple instruction, multiple data, or MIMD, computers is, for the most part, divided into distributed-memory and shared-memory systems. From a programmer's point of view, a distributed-memory system consists of a collection of core-memory pairs connected by a network, and the memory associated with a core is directly accessible only to that core. See Figure 1 [21], [22], [23], [24]. 
International Journal of Computer Science \& Information Technology (IJCSIT) Vol 10, No 5, October 2018

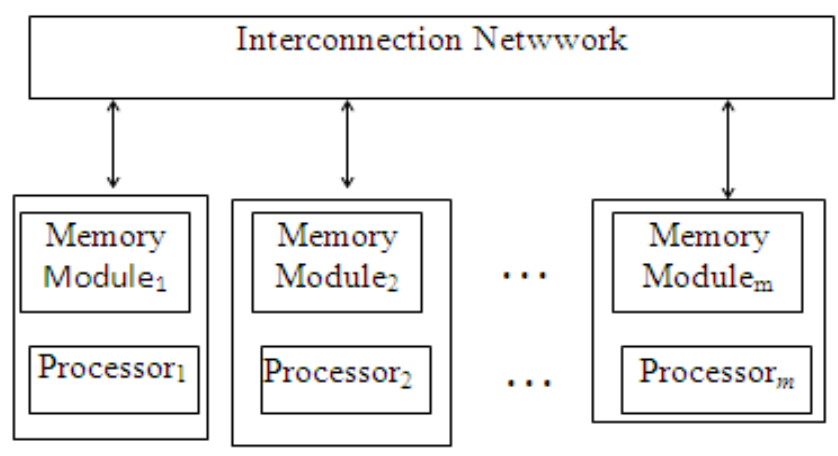

Figure 1. Model of adistributed-memory system

In message-passing programs, a program running on one core-memory pair is usually called a process, and two processes can communicate by calling functions: one process calls a send function and the other calls a receive function. The implementation of message-passing that we'll be using is called MPI, which is an abbreviation of Message-Passing Interface. MPI is not a new programming language. It defines a library of functions that can be called from C, C, and Fortran programs. We'll learn about some of MPI's different send and receive functions.

I used MPI to parallelize the computation and got exact results. Moreover, the execution time by parallel algorithms is much shorter than one by sequential algorithm. If $n=10, n^{\prime}=1$, then the number of processors $\mathrm{k}=2^{\mathrm{n}^{\prime}}+1=3$. Only Rank 1 and rank 2 do calculations and send results to Rank 0.
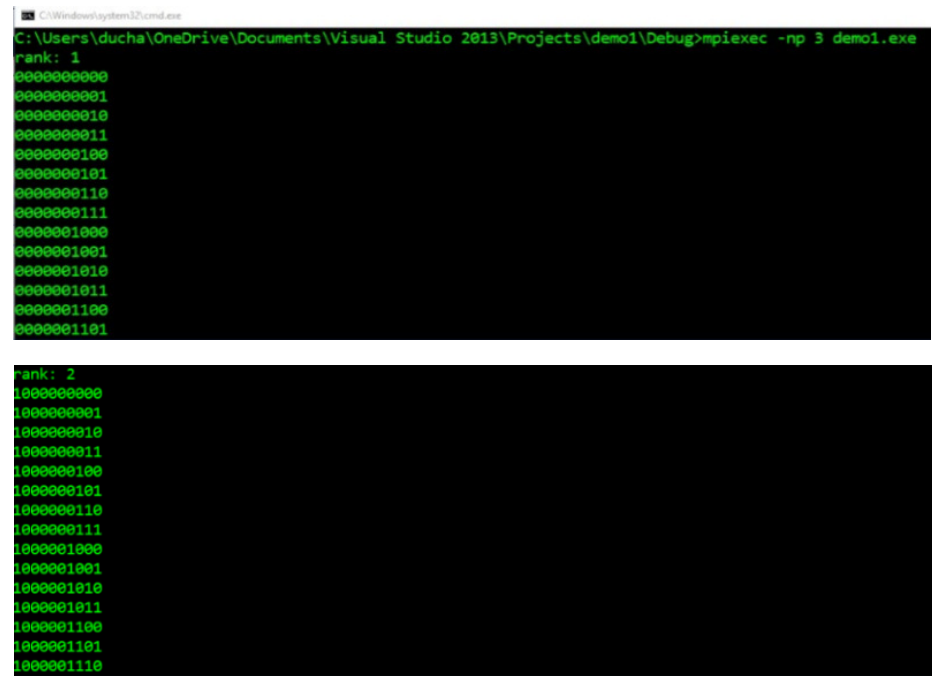

Figure 2. Demo result

Table 1. The execution time (ms) with $\mathrm{n}=12$ on the sequential (Seq) and parallel (Par)

\begin{tabular}{|c|c|c|c|c|}
\hline $\mathrm{n}=12$ & Seq & Par_3p & Par_5p & Par_9p \\
\hline $\begin{array}{c}\text { ime } \\
(\mathrm{ms})\end{array}$ & 46761 & 26710 & 15617 & 9162 \\
\hline
\end{tabular}




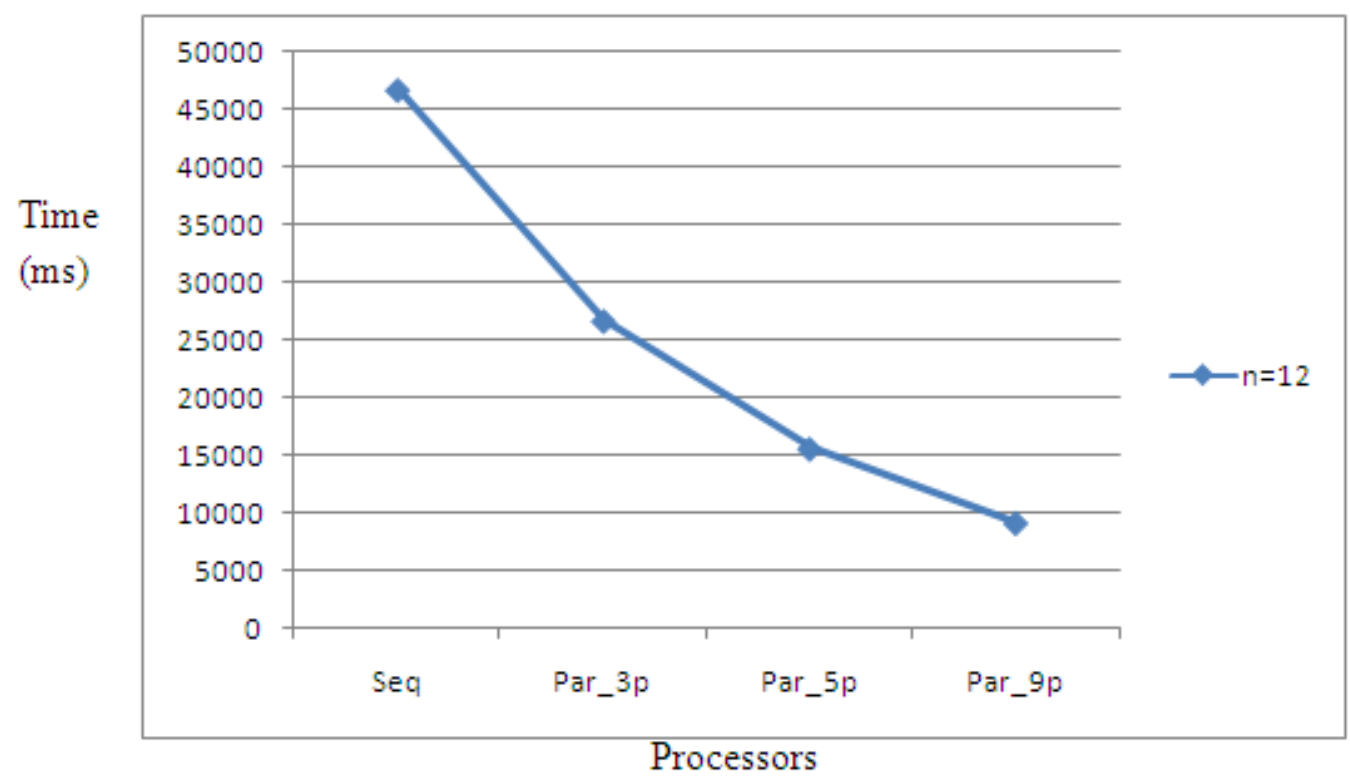

Figure 3. The graph illustrates execution time of the binary sequence with $n=12$ on the Processors

It is noted that when $\mathrm{n}$ is big, the parallel algorithm will reduce the execution time as compared to the sequential algorithm. When we increase the number of processors, the execution time will decrease dramatically. However, when we increase the number of processors at a certain point, execution time does not reduce but increases.

\section{The Algorithm Listing Permutations Of N Elements}

\subsection{SUBSTITUTION, INVERSION}

Based on linear algebra theory and the study [1], the concepts of substituend, inversion are presented as follows:

Let set $X_{n}=\{1,2,3, \ldots, n\},(n \geq 1)$. A bijection $\sigma: X_{n} \rightarrow X_{n}$ is called a substituendon the set $X_{n}$

The set of all substituends on the set $X_{n}$ is labeled $S_{n}$

Substituend $\sigma: \mathrm{X}_{\mathrm{n}} \rightarrow \mathrm{X}_{\mathrm{n}}$ is demonstrated as follows:

$$
\sigma=\left(\begin{array}{ccrcc}
1 & 2 & 3 & \ldots \ldots \ldots \ldots n \\
\sigma(1) & \sigma(2) & \sigma(3) & \ldots \ldots \ldots \sigma(n)
\end{array}\right)
$$

where $\sigma(i)$ is the image of the element $i \in \mathrm{X}_{n}$ written on the bottom line, in the same column as $\mathrm{i}$.

For example.

$$
\sigma=\left(\begin{array}{llll}
1 & 2 & 3 & 4 \\
3 & 2 & 4 & 1
\end{array}\right)
$$


is the substituendon the set $\mathrm{X}_{4}=\{1,2,3,4\}$ determined by: $\sigma(1)=3, \sigma(2)=2, \sigma(3)=4, \sigma(4)=$ 1 .

Then the number of substituendson the set $X_{n}$ is equal to the number of permutations on that set and is $n !$. Thus, $S_{n}$ has $n$ ! elements.

Suppose there exists a substituend on the set $X_{n}$. with $i, j \in X_{n}, i \neq j$, the pair $(\sigma(i), \sigma(j))$ is aninversion of $\sigma$ if $i<j$ but $\sigma(i)>\sigma(j)$.

For example. Let $X_{3}$, the substituend $\sigma_{2}=\left(\begin{array}{lll}1 & 2 & 3 \\ 2 & 3 & 1\end{array}\right)$ has two inversions: $(2,1),(3,1)$. the substituend $\tau_{2}=\left(\begin{array}{lll}1 & 2 & 3 \\ 3 & 2 & 1\end{array}\right)$ has three inversions: $(3,2),(3,1),(2,1)$.

Set $X_{n}$ has $n$ ! permutations and $n$ ! substituend. the inversion sequence on every substituend can be defined as follows: the value of inversion of element 1 in the substituend is assigned to that inversion sequence, the value of inversion of element 2 in the substituend is assigned to the inversion sequence. Let's continue with this for $\mathrm{n}$ elements. The following is the inversion sequence with $\mathrm{n}=4$.

Table 2. Substituend, inversion sequence and inversion vector sequence with $n=4$

\begin{tabular}{|c|c|c|c|}
\hline $\mathbf{N}_{\mathbf{0}}$ & Permutation & inversion & Inversion vector \\
\hline 1 & 1234 & 0000 & 0000 \\
\hline 2 & 2134 & 1000 & 0001 \\
\hline 3 & 2314 & 2000 & 0002 \\
\hline 4 & 2341 & 3000 & 0003 \\
\hline 5 & 1324 & 0100 & 0010 \\
\hline 6 & 3124 & 1100 & 0011 \\
\hline 7 & 3214 & 2100 & 0012 \\
\hline 8 & 3241 & 3100 & 0013 \\
\hline 9 & 1342 & 0200 & 0020 \\
\hline 10 & 3142 & 1200 & 0021 \\
\hline 11 & 3412 & 2200 & 0022 \\
\hline 12 & 3421 & 3200 & 0023 \\
\hline 13 & 1243 & 0010 & 0100 \\
\hline 14 & 2143 & 1010 & 0101 \\
\hline 15 & 2413 & 2010 & 0102 \\
\hline 16 & 2431 & 3010 & 0103 \\
\hline 17 & 1423 & 0110 & 0110 \\
\hline 18 & 4123 & 1110 & 0111 \\
\hline 19 & 4213 & 2110 & 0112 \\
\hline 20 & 4231 & 3110 & 0113 \\
\hline 21 & 1432 & 0210 & 0120 \\
\hline 22 & 4132 & 1210 & 0121 \\
\hline 23 & 4312 & 2210 & 0122 \\
\hline 24 & 4321 & 3210 & 0123 \\
\hline
\end{tabular}

Table 1 shows that a permutation always has an Inversion vector and an Inversion vector always has a permutation. Thus, instead of looking for the permutation of $n$ elements in the order of the 
dictionary methods. The study comes up with a new idea is that to work on the permutations by finding the Inversion vector sequence. Inversion vector sequence (bounded sequence) is created with the initial sequence 0000 and with final sequence 0123 with $n=4$.

\subsection{BOUNDED SEQUENCES}

The set of integers is represented by the letter $Z$. Let $\mathrm{n}$ be a positive integer, assume that $\mathrm{p}$ and $\mathrm{q}$ are two integer sequences of length $\mathrm{n}$ and denoted as follows:

$\mathrm{p}=\left(\mathrm{p}_{1} \mathrm{p}_{2} \ldots \mathrm{p}_{\mathrm{n}}\right), \mathrm{q}=\left(\mathrm{q}_{1} \mathrm{q}_{2} \ldots \mathrm{q}_{\mathrm{n}}\right) \mid \mathrm{p}_{\mathrm{i}}, \mathrm{q}_{\mathrm{i}} \in Z, \forall i \in 1, \ldots, n$

We have the following definition:

1) $\mathrm{p} \leq \mathrm{q}$ If and only if $\mathrm{p}_{\mathrm{i}} \leq \mathrm{q}_{\mathrm{i}} \forall i \in 1, \ldots, n$

2) $\mathrm{p}<\mathrm{q}$ If and only if $\exists j \in(1 \ldots n): \mathrm{p}_{\mathrm{j}}<\mathrm{q}_{\mathrm{j}}$ and $\left.\mathrm{p}_{\mathrm{i}} \leq \mathrm{q}_{\mathrm{i}}: \forall i \in 1, \ldots, n\right)$ and $\mathrm{i} \neq j$

Bounded sequence problems are demonstrated as follows:

Given two integer sequences $\mathrm{s}$ and $\mathrm{g}$ of length $\mathrm{n}$, such that $\mathrm{s}<\mathrm{g}$, find all sequences $\mathrm{t}$ of length $\mathrm{n}$ such that $\mathrm{s} \leq \mathrm{t} \leq \mathrm{g}$

Let $\mathrm{s}=\left(\mathrm{s}_{1} \mathrm{~s}_{2} \ldots \mathrm{s}_{\mathrm{n}}\right)$ and $\mathrm{g}=\left(\mathrm{g}_{1} \mathrm{~g}_{2} \ldots \mathrm{g}_{\mathrm{n}}\right)$, be two bound. The sequence $\mathrm{t}=\left(\mathrm{t}_{1} \mathrm{t}_{2} \ldots \mathrm{t}_{\mathrm{n}}\right)$ must satisfy:

$$
\mathrm{t}_{\mathrm{i}} \in Z \wedge s_{i} \leq t_{i} \leq g_{i} \forall i \in(1 \ldots n)(3)
$$

Example: Let $\mathrm{s}=\left(\begin{array}{llll}0 & 0 & 0 & 0\end{array}\right), \mathrm{g}=\left(\begin{array}{llll}0 & 1 & 2 & 3\end{array}\right)$ be two bounds, integer sequences $\mathrm{t}$ satisfy $\mathrm{s} \leq \mathrm{t} \leq \mathrm{g}$. Thus, $\mathrm{t}$ is arranged in ascending dictionary order as in the following table:

Table 3.Bounded sequence $\mathrm{t}$ with $\mathrm{s}=\left(\begin{array}{llll}0 & 0 & 0 & 0\end{array}\right), \mathrm{g}=\left(\begin{array}{llll}0 & 1 & 2 & 3\end{array}\right)$

\begin{tabular}{|c|c|c|c|c|c|c|c|c|c|c|c|}
\hline $\mathbf{N}_{\mathrm{o}}$ & $\begin{array}{l}\text { Bounded } \\
\text { equence } t\end{array}$ & $\mathbf{N}_{\mathbf{o}}$ & $\begin{array}{c}\text { Bounded } \\
\text { sequence } \\
t\end{array}$ & $\mathbf{N}_{\mathrm{o}}$ & $\begin{array}{c}\text { Bounded } \\
\text { sequence } \\
t\end{array}$ & $\mathbf{N}_{\mathbf{o}}$ & $\begin{array}{c}\text { Bounded } \\
\text { sequence } \\
\mathbf{t}\end{array}$ & $\mathbf{N}_{\mathrm{o}}$ & \begin{tabular}{|c|}
$\begin{array}{c}\text { Bounded } \\
\text { sequence } \\
\mathbf{t}\end{array}$ \\
\end{tabular} & $\mathbf{N}_{0}$ & $\begin{array}{c}\text { Bounded } \\
\text { sequence } \\
\mathbf{t}\end{array}$ \\
\hline 1 & $\overline{0}$ & 5 & $\begin{array}{lllll}0 & 0 & 1 & 0\end{array}$ & 9 & $0 \begin{array}{lllll}0 & 0 & 2 & 0\end{array}$ & 13 & $\begin{array}{lllll}0 & 1 & 0 & 0\end{array}$ & 17 & $\begin{array}{llllll}0 & 1 & 1 & 0\end{array}$ & 21 & 0120 \\
\hline 2 & 0 & 6 & 11 & 10 & 1 & 14 & 1 & 18 & $\begin{array}{lllll}0 & 1 & 1 & 1\end{array}$ & 22 & 01221 \\
\hline 3 & 000002 & 7 & 12 & 11 & 22 & 15 & 02 & 19 & 01112 & 23 & 0122 \\
\hline 4 & $0 \begin{array}{llll}0 & 0 & 0 & 3\end{array}$ & 8 & $\begin{array}{lllll}0 & 0 & 1 & 3\end{array}$ & 12 & 0023 & 16 & $0 \begin{array}{llll}0 & 1 & 0 & 3\end{array}$ & 20 & $0 \begin{array}{llll}0 & 1 & 1 & 3\end{array}$ & 24 & 0123 \\
\hline
\end{tabular}

Theorem 1. Given two bounds $s=\left(\begin{array}{lll}0 & \ldots & 0\end{array}\right)$ (with $n$ elements 0$)$ and $g=\left(\begin{array}{lllll}0 & 1 & 2 & \ldots & \mathrm{n}-1\end{array}\right)$. The bounded sequence t satisfy $s \leq t \leq g$ which is the inversion vector of the set $X_{n}=\{1,2,3, \ldots, n\},($ $\mathrm{n} \geq 1)$. The sequence $\mathrm{t}$ is equals to $\mathrm{n}$ ! and the inversion Vector $\mathrm{s}=(0 \ldots 0)$ corresponds to the permutation $\left(\begin{array}{llll}1 & 2 & \ldots\end{array}\right)$ and the inversion Vector $g=\left(\begin{array}{lllll}0 & 1 & 2 & \ldots & n-1\end{array}\right)$ corresponds to the permutation (n n-1 ... 1).

Proof: See [1]

Theorem 2. Lets $=\left(s_{1} s_{2} \ldots s_{n}\right)$ and $g=\left(g_{1} g_{2} \ldots g_{n}\right)$ be two bounds. The sequences $t=\left(t_{1} t_{2} \ldots t_{n}\right)$ are bounded sequences. Let $\mathrm{C}$ be the number of bounded sequences $t$. Then we have:

Proof: See [1]

$$
\mathrm{C}=\prod_{i=1}^{n}\left(g_{i}-s_{i}+1\right)(4)
$$




\section{Algorithm 4. Creating bounded sequence (s(n), g(n))}

1. BEGIN

2. Input $\mathrm{n}, \mathrm{s}[\mathrm{i}], \mathrm{g}[\mathrm{i}], \mathrm{i}=1, \ldots, \mathrm{n} / / \mathrm{s}, \mathrm{g}$ : two bounds

3. $\mathrm{t}[\mathrm{i}]:=\mathrm{s}[\mathrm{i}], \mathrm{i}=1, \ldots, \mathrm{n}$

4. Repeat

5. Print $t[i], i=1, \ldots, n$

6. $\mathrm{i}:=\mathrm{n}$;

7. While $t[\mathrm{i}]=\mathrm{g}[\mathrm{i}]$ do

8. Begin
a. $\mathrm{t}[\mathrm{i}]:=\mathrm{s}[\mathrm{i}]$;
b. $\mathrm{i}:=\mathrm{i}-1$;

9. End;

10. If $\mathrm{i}>=1$ then $\mathrm{t}[\mathrm{i}]:=\mathrm{t}[\mathrm{i}]+1$;

11. Untill $i=0$

12. END.

\subsection{PARAllel algorithm listing PERMUtations OF N ELEMENTS}

Algorithm finding the permutation of $\mathrm{n}$ elements by the dictionary method is sometimes challenging to determine the input and the end conditions of the processors. Thus, it is crucial to propose a parallel algorithm to find the permutations of $n$ elements based on the bounded sequence to divide the bounded sequences for the processors.

\subsubsection{THE IDEAS OF THE ALGORITHMS}

If $n$ increases, then the permutation is very large ( $n !)$. Therefore, a parallel algorithm must be built to improve computing performance.

The idea of parallel algorithms is to utilize k processors, which have a main processor called processor 0 , and sub processors called $\mathrm{k}-1$. The main processor receives the sequence $\mathrm{s}$ [i] and $\mathrm{g}$ [i] that are the two bounds as in algorithm 4 . The main processor will find $\mathrm{k}$ bound sequences and send these $\mathrm{k}$ sequences for the sub processors to find the bounded sequences and convert

$$
\mathrm{g}_{0}=(0 \ldots 0 \text { p n-1) (5) }
$$

them into permutation sequences. $k$ Processor depends on $\mathrm{p}$ with $\mathrm{k}:=\mathrm{p} !, \mathrm{p}=(2,3, \ldots, \mathrm{n}-1)$. Given that $\mathrm{p}$ is chosen, the first bound has the smallest sequence: $\mathrm{s}_{0}=0 \ldots 0$ (n number 0 ) and the largest sequence: 
he smallest sequence of the 2 segment is:

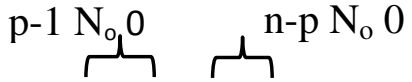

$$
\begin{aligned}
& \mathrm{s}_{1}=\left(\begin{array}{lllllll}
0 & \ldots & 0 & 1 & 0 & \ldots & 0
\end{array}\right)
\end{aligned}
$$

Thus, the sequence $\mathrm{g}_{\mathrm{i}}(\mathrm{i}=0, \ldots \mathrm{k}-1)$ is obtained by finding the bounded sequence of $\mathrm{s}^{\prime}[\mathrm{i}]=0 \ldots 0$ $\left(\mathrm{p}-1 \mathrm{~N}_{\mathrm{o}} 0\right)$ and $\mathrm{g}^{\prime}[\mathrm{i}]=\mathrm{i}, \mathrm{i}=1, \ldots, \mathrm{p}-1$. After finding the bounded sequence, 0 is inserted to the left side of the bounded sequence and $\mathrm{p}, \ldots, \mathrm{n}-1$ are inserted to the right side of the bounded sequence. We has $g_{i}$

Based on $\mathrm{g}_{\mathrm{i}-1} . \mathrm{s}_{\mathrm{i}}$. is found as follows:

$\mathrm{m}=\operatorname{Max}\left(j, \mathrm{~g}_{\mathrm{i}-1}[\mathrm{j}]<\mathrm{g}[\mathrm{j}]\right.$, The value of $\mathrm{s}_{\mathrm{i}}[1]$ to $\mathrm{s}_{\mathrm{i}}[\mathrm{m}-1]$ is unchanged, ie $\mathrm{g}_{\mathrm{i}-1}[\mathrm{a}], \mathrm{a}=1, \ldots, \mathrm{m}-1$ $\mathrm{s}_{\mathrm{i}}[\mathrm{m}]:=\mathrm{g}_{\mathrm{i}-1}[\mathrm{~m}]+1$

$\mathrm{s}_{1}[\mathrm{i}]=0, \mathrm{i}=\mathrm{m}+1, \ldots, \mathrm{n}$

For example: Let $\mathrm{n}=4$, choose $\mathrm{p}=3, \mathrm{k}=6$, then we have 3 ! $=6$ segments. These six segments are allocated to 6 sub processors shown in Table 3

Table 4. Six segments are allocated to 6 sub processors

\begin{tabular}{|c|c|c|c|c|c|c|c|c|c|c|c|}
\hline $\mathbf{N}_{\mathrm{o}}$ & $\begin{array}{c}\text { Bounded } \\
\text { sequence } \\
t\end{array}$ & $\mathbf{N}_{\mathbf{o}}$ & $\begin{array}{c}\text { Bounded } \\
\text { sequence } \\
\mathbf{t}\end{array}$ & $\mathbf{N}_{\mathrm{o}}$ & $\begin{array}{c}\text { Bounded } \\
\text { sequence } \\
\mathbf{t}\end{array}$ & $\mathbf{N}_{\mathrm{o}}$ & $\begin{array}{c}\text { Bounded } \\
\text { sequence } \\
\mathbf{t}\end{array}$ & $\mathbf{N}_{\mathbf{o}}$ & $\begin{array}{c}\text { Bounded } \\
\text { sequence } \\
\mathbf{t}\end{array}$ & $\mathbf{N}_{\mathrm{o}}$ & $\begin{array}{c}\text { Bounded } \\
\text { sequence } \\
t\end{array}$ \\
\hline 1 & 00000 & 5 & $\begin{array}{lllll}0 & 0 & 1 & 0\end{array}$ & 9 & 00020 & 13 & $\begin{array}{lllll}0 & 1 & 0 & 0\end{array}$ & 17 & $\begin{array}{llllll}0 & 1 & 1 & 0\end{array}$ & 21 & 01120 \\
\hline 2 & & 6 & & 10 & & 14 & & 18 & & 22 & 21 \\
\hline 3 & 00002 & 7 & 2 & 11 & 0022 & 15 & 0102 & 19 & 01112 & 23 & 22 \\
\hline 4 & $0 \begin{array}{llll}0 & 0 & 0 & 3\end{array}$ & 0 & 00013 & 12 & 0023 & 16 & 010103 & 20 & $0 \begin{array}{llll}0 & 1 & 13\end{array}$ & 24 & 0123 \\
\hline \multicolumn{2}{|c|}{$\begin{array}{c}\text { Segment } 1: \\
\left(\mathrm{s}_{1}, \mathrm{~g}_{1}\right) \\
=(0000,0003)\end{array}$} & \multicolumn{2}{|c|}{$\begin{array}{c}\text { Segment 2: } \\
\left(\mathrm{s}_{2}, \mathrm{~g}_{2}\right) \\
=(0010,0013)\end{array}$} & \multicolumn{2}{|c|}{$\begin{array}{c}\text { Segment 3: } \\
\left(\mathrm{s}_{3}, \mathrm{~g}_{3}\right) \\
=(0020,0023)\end{array}$} & \multicolumn{2}{|c|}{$\begin{array}{l}\text { Segment } 4: \\
\left(\mathrm{s}_{4}, \mathrm{~g}_{4}\right) \\
=(0100,0103)\end{array}$} & \multicolumn{2}{|c|}{$\begin{array}{l}\text { Segment5: }\left(\mathrm{s}_{5}, \mathrm{~g}_{5}\right) \\
=(0110,0113)\end{array}$} & \multicolumn{2}{|c|}{$\begin{array}{c}\text { Segment 6: } \\
\left(\mathrm{s}_{6}, \mathrm{~g}_{6}\right) \\
=(0120,0123)\end{array}$} \\
\hline
\end{tabular}

\subsubsection{Parallel Algorithm}

Processors number $\mathrm{k}=\mathrm{p}$ !; $\mathrm{p}=(2,3, \ldots, \mathrm{n}-1)$

\section{Algorithm 5: Parallel algorithm finding permutation of $\mathbf{n}$ elements}

\{

1. Input $n, p(p \in\{2,3, \ldots, n-1\})$

2. $\mathrm{s}[\mathrm{i}]:=0 \forall i=1, \ldots, n$

3. $\mathrm{g}[\mathrm{i}+1]:=\mathrm{i} \forall i=0,1, \ldots, n-1$

4. $\mathrm{k}:=\mathrm{p} ! ; \mathrm{p}=(2,3, \ldots, \mathrm{n}-1) / / \mathrm{k}$ is processors

5. //The main processor finds $\mathrm{k}$ subsegments, then divides to the subprocessors If $\mathrm{k}=1(\mathrm{Rank}=1)$ then \{

// Find the bounded by algorithm 4 and send data to subprocessors

5.1. $\mathrm{s}^{\prime}[\mathrm{i}]=0, \mathrm{i}=1, \ldots, \mathrm{p}-1$ 
International Journal of Computer Science \& Information Technology (IJCSIT) Vol 10, No 5, October 2018

5.2. $\mathrm{g}^{\prime}[\mathrm{i}]=\mathrm{i}, \mathrm{i}=1, \ldots, \mathrm{p}-1$

5.3. $\quad c_{\mathrm{j}}:=$ Algorithm $4\left(\mathrm{~s}^{\prime}(\mathrm{i}), \mathrm{g}^{\prime}(\mathrm{i})\right), \mathrm{j}=1, \ldots, \mathrm{k}$.

5.4. $\quad$ Send(s[i] $=0, \forall i=1, \ldots, \mathrm{n}$ to $\left.\mathrm{p}_{1}\right)$

5.5. Send $\left(c_{j}\right.$ to $p_{j}(j=1, \ldots, k)$

5.6. Send $\left(c_{j}\right)$ to $p_{j+1}(j=1$ to $k-1)$

6.7. Send $\mathrm{g}[\mathrm{i}]$ in step 4 to subprocessors

\}

\section{6. // Subprocessors perform concurrently}

\{

6.1. Receive(data)

6.2. Insert element 0 to the left of $c_{j}(j=1, \ldots, k) / / j$ is the index of the $\mathrm{k}$ processors

6.3. Insert the elements $p, p+1, \ldots n-1$ to the right of $c_{j}(j=1, \ldots, k)$

6.4. $\mathrm{g}_{\mathrm{j}}:=\mathrm{c}_{\mathrm{j}}(\mathrm{j}=1,2, \ldots, \mathrm{k}) / / \mathrm{g}_{\mathrm{j}}$ is the largest bound sequence.

6.5. The subprocessor $\mathrm{p}_{1}$ initiates $\mathrm{s}_{1}: \mathrm{s}_{1}[\mathrm{i}]:=0 \forall \mathrm{i}=1, \ldots, \mathrm{n} / / \mathrm{s}_{1}$ is the smallest bound sequence on processor $\mathrm{p}_{1}$.

// the Subprocessor $\mathrm{p}_{2}, \mathrm{p}_{3}, \ldots, \mathrm{p}_{\mathrm{k}}$ find the smallest bound sequence as follows::

6.6. $\mathrm{i}:=\mathrm{n}$;

6.7. While $\mathrm{c}_{\mathrm{j}-1}[\mathrm{i}]=\mathrm{g}[\mathrm{i}]$ do

6.8. Begin

6.9. $\quad \mathrm{c}_{\mathrm{j}-1}[\mathrm{i}]:=0$;

6.10. $\mathrm{i}:=\mathrm{i}-1$;

6.11. End;

6.12. If $\mathrm{i}>=1$ then $\mathrm{c}_{\mathrm{j}-1}[\mathrm{i}]:=\mathrm{c}_{\mathrm{j}-1}[\mathrm{i}]+1$;

6.13. $\mathrm{s}_{\mathrm{j}}[\mathrm{i}]:=\mathrm{c}_{\mathrm{j}-1}[\mathrm{j}], \mathrm{i}=1, \ldots, \mathrm{n}, \mathrm{j}=2, \ldots, \mathrm{k}$

7. $\mathrm{t}_{\mathrm{j}}[\mathrm{i}]:=$ Algorithm $4\left(\mathrm{~s}_{\mathrm{j}}(\mathrm{i}), \mathrm{g}_{\mathrm{j}}(\mathrm{i})\right), \mathrm{j}=1, \ldots, \mathrm{k}, \mathrm{i}=1, \ldots, \mathrm{n}$.

8. Convert all bounded sequences $t_{j}[i]$ to permutation sequences

9. Send permutations sequences to main processor.

10. The main processor print results and ends.

Theorem 3: The Parallel algorithm is TRUE.

Proof:

First, we need to prove that the bound sequences $\mathrm{s}_{\mathrm{j}}$ and $\mathrm{g}_{\mathrm{j}}$ on $\mathrm{k}$ processors satisfy the formula (3), ie, $s_{j}$ and $g_{j}$ are in the bounded sequence with the smallest bound sequence $s[i]:=0 \forall i=1, \ldots, n$, and the largest bound sequence $g[i+1]:=i \forall i=0,1, \ldots, n-1$.

$\mathrm{g}_{\mathrm{j}}$ is computed in step 6.3 in the parallel algorithm by inserting 0 to the left of $\mathrm{t}$ and inserting $\mathrm{p}, \mathrm{p}$ $+1, \mathrm{n}-1$ to the right of $\mathrm{c}_{\mathrm{j},}$, then $\mathrm{g}_{\mathrm{j}}[\mathrm{i}] \leq \mathrm{g}[\mathrm{i}], \mathrm{i}=1, \ldots, \mathrm{n} . \mathrm{s}_{\mathrm{j}+1}$ is based on the $\mathrm{g}_{\mathrm{j}}$ given from steps 7.6 to 7.13. there always exists $\mathrm{s}[\mathrm{i}] \leq \mathrm{s}_{\mathrm{j}}[\mathrm{i}], \mathrm{i}=1, \ldots, \mathrm{n}$. Thus $\mathrm{s}_{\mathrm{j}}$ and $\mathrm{g}_{\mathrm{j}}$ satisfy the formula (3) with 2 bound sequences $\mathrm{s}[\mathrm{i}]$ and $\mathrm{g}[\mathrm{i}], \mathrm{i}=1, \ldots, \mathrm{n}$.

Next, we prove that the total number of bounded sequences in the $k$ processors is $n$ ! 
When $\mathrm{p}(\mathrm{p} \in\{2,3, \ldots, \mathrm{n}-1\})$ is chosen, the number of processors involved in finding the bounded sequences is $\mathrm{k}=\mathrm{p}$ ! (Note that the number of processors to find bounded sequences are equal.)

The smallest bound sequence of $\mathrm{p}_{1}$ is $\mathrm{s}_{1}=(0 \ldots .0)$ (n number 0$)$ and the largest bound sequence is $\mathrm{g}_{1}$ based on formula (5). According to the solution in (4), the number of bounded sequence in segment 1 that the subprocessor $\mathrm{p}_{1}$ has done is $\prod_{i=p}^{n-1}(i+1)$. Each subprocessor will also find the number of bounded sequences equal to $\prod_{i=p}^{n-1}(i+1)$. In addition, $\mathrm{s}_{\mathrm{j}}$ and $\mathrm{g}_{\mathrm{j}}$ are two bound sequences on the subprocessor $\mathrm{p}_{\mathrm{j}}$, then $s_{j}[i]=g_{j}[i], \forall i=1, \ldots, p$ and $s_{j}[i]=0, \forall i=p+$ $1, \ldots, n$ and $g_{j}[i]=i, \forall i=p, \ldots, n-1 .$. Applying the formula (4) to the two bound sequences $\mathrm{s}_{\mathrm{j}}$ and $\mathrm{g}_{\mathrm{j}}$, the number of bounded sequence to each processor is $\prod_{i=p}^{n-1}(i+1)=(\mathrm{p}+1) \cdot(\mathrm{p}+2) \ldots \ldots \mathrm{n}$. On the other hand, we have the number of processors $\mathrm{k}=\mathrm{p}$ ! So the number of buonded sequences by the $k$ processors is:

$\mathrm{k} \cdot(\mathrm{p}+1) \cdot(\mathrm{p}+2) \ldots \ldots . \mathrm{n}=\mathrm{p} !(\mathrm{p}+1) \cdot(\mathrm{p}+2) \ldots . . \mathrm{n}=\mathrm{n}$ ! Thus, the number of bounded sequences on the $k$ processors is $n$ ! which is equal to permutation $n$ !.

\subsubsection{EXPERIMENTAL RESULTS}

The algorithm is implemented in the computer with its configuration:

Processor: corei7 2.6GHz and disk: write $28-30 \mathrm{Mb} / \mathrm{s}$

- Interface on the main processor $\mathrm{P}_{1}$ : In this main interface, we need to select $\mathrm{n}$ and the number of subprocessors (Figure 4).

- Interface for the sub processors $\mathrm{P}_{\mathrm{i}}(\mathrm{i}=1,2 \ldots, \mathrm{k})$ (Figure 5)

- Resulting interface on the main processor $\mathrm{P}_{1}$. The permutation result is saved as a file (Figure 6).

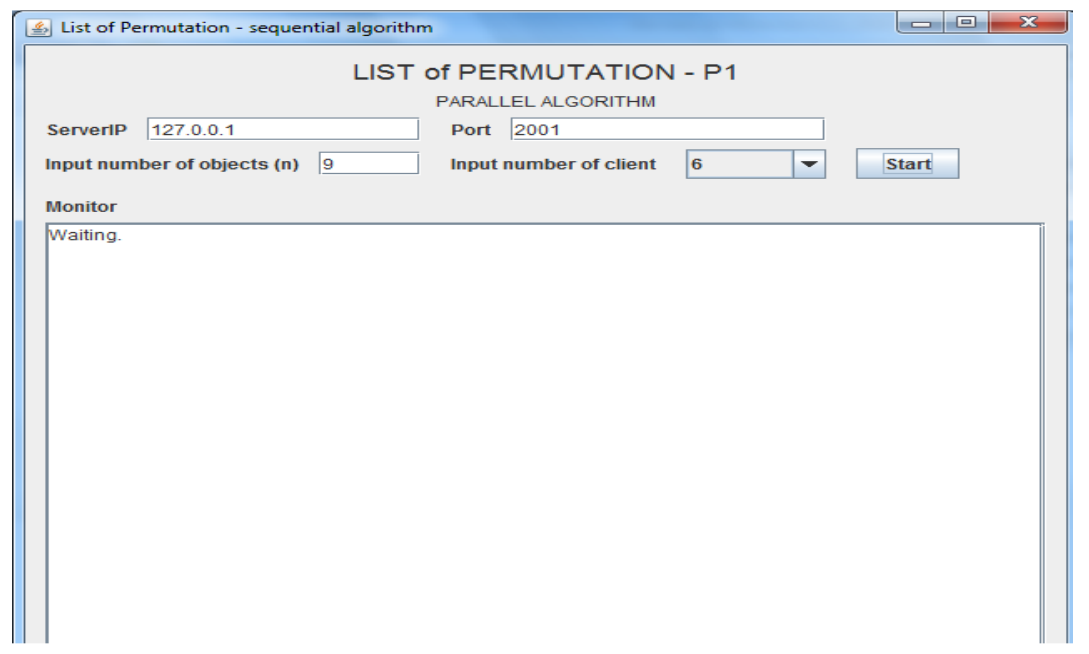

Figure 4. Interface of main processor $\mathrm{P}_{1}$ 
International Journal of Computer Science \& Information Technology (IJCSIT) Vol 10, No 5, October 2018

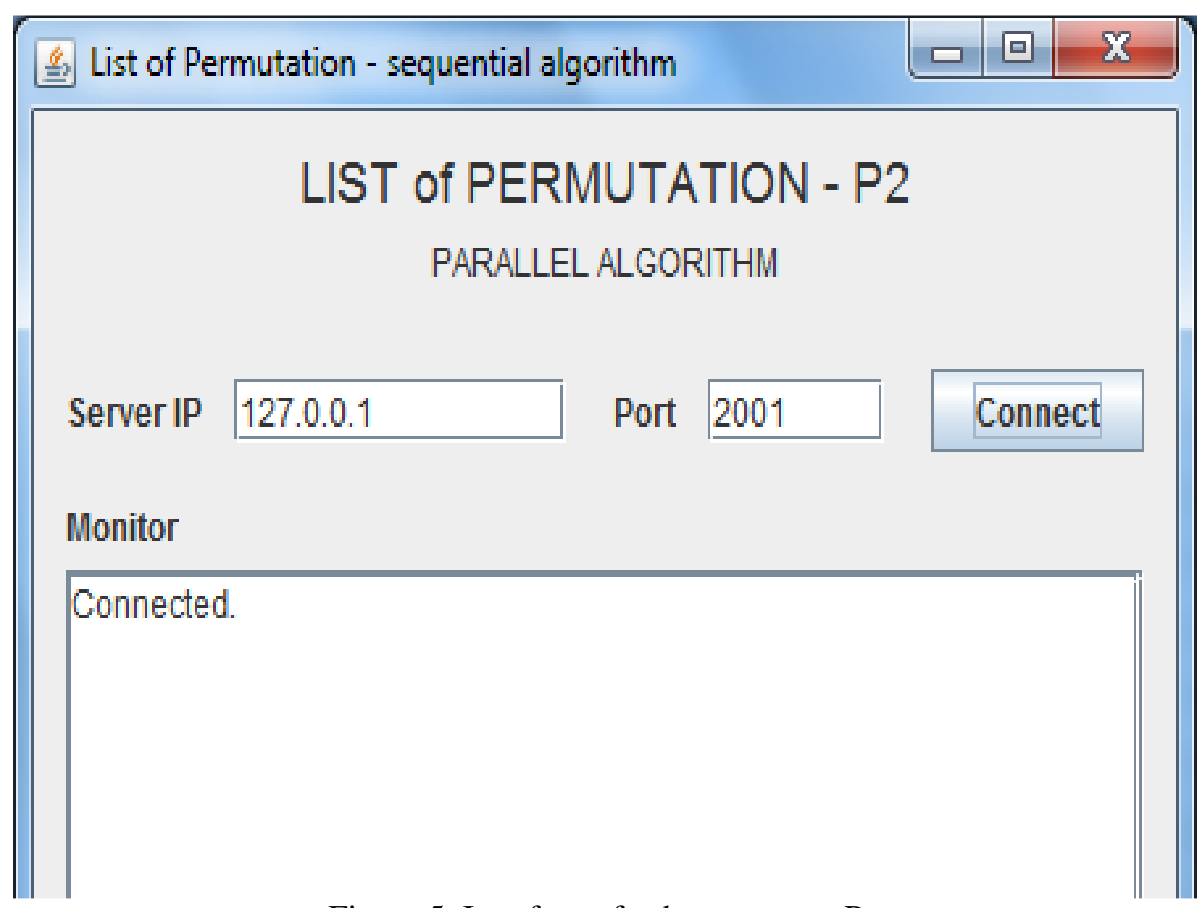

Figure 5. Interface of sub processors $\mathrm{P}_{\mathrm{i}}$

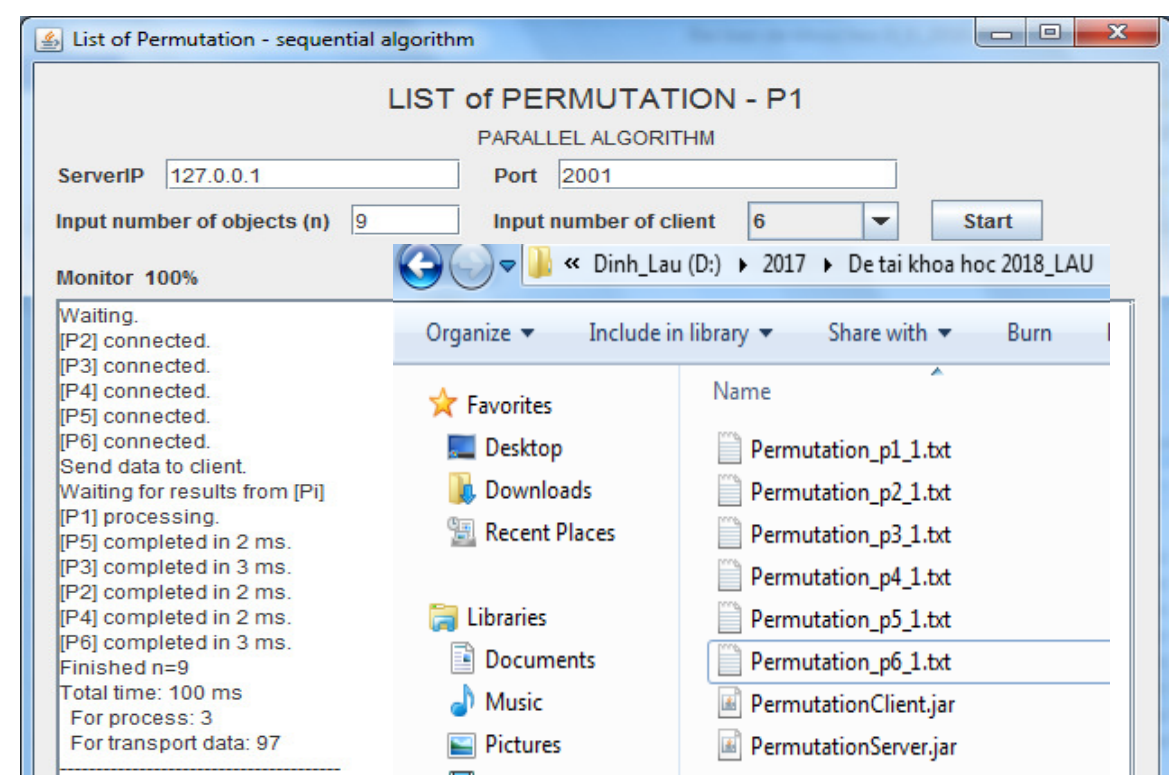

Figure 6. Interface results of the main processor $\mathrm{P}_{1}$ 
International Journal of Computer Science \& Information Technology (IJCSIT) Vol 10, No 5, October 2018

Table 4. The execution time (ms) on the sequential (Seq) and parallel (Par) (n=9 to 12)

\begin{tabular}{|l|l|l|l|l|}
\hline N & Seq & Par_2p & Par_6p & Par_24p \\
\hline 9 & 323 & 234 & 100 & 97 \\
\hline 10 & 3200 & 1879 & 691 & 151 \\
\hline 11 & 45985 & 24061 & 8481 & 2190 \\
\hline 12 & 1143542 & 581107 & 210590 & 27228 \\
\hline
\end{tabular}

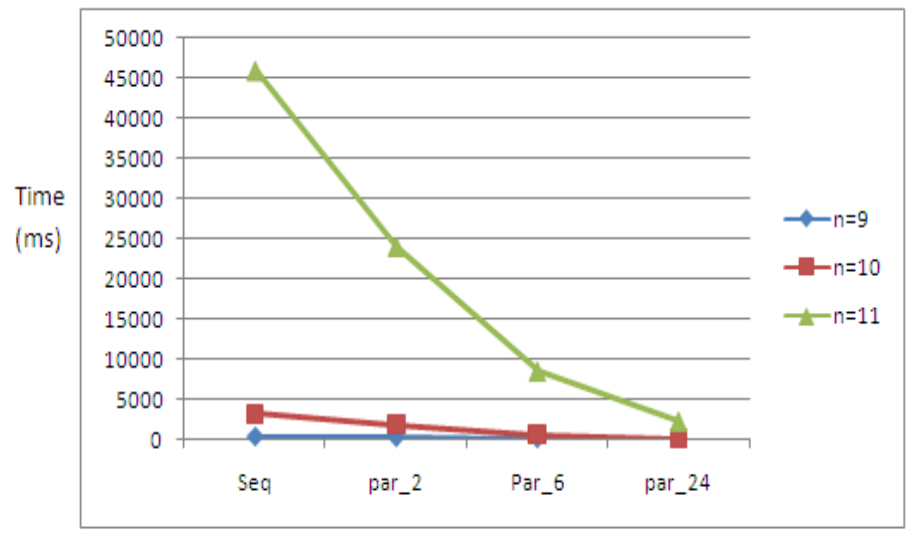

Processors

Figure 7. The graph illustrates time listing permutation of $\mathrm{n}$ elements by the subprocessors

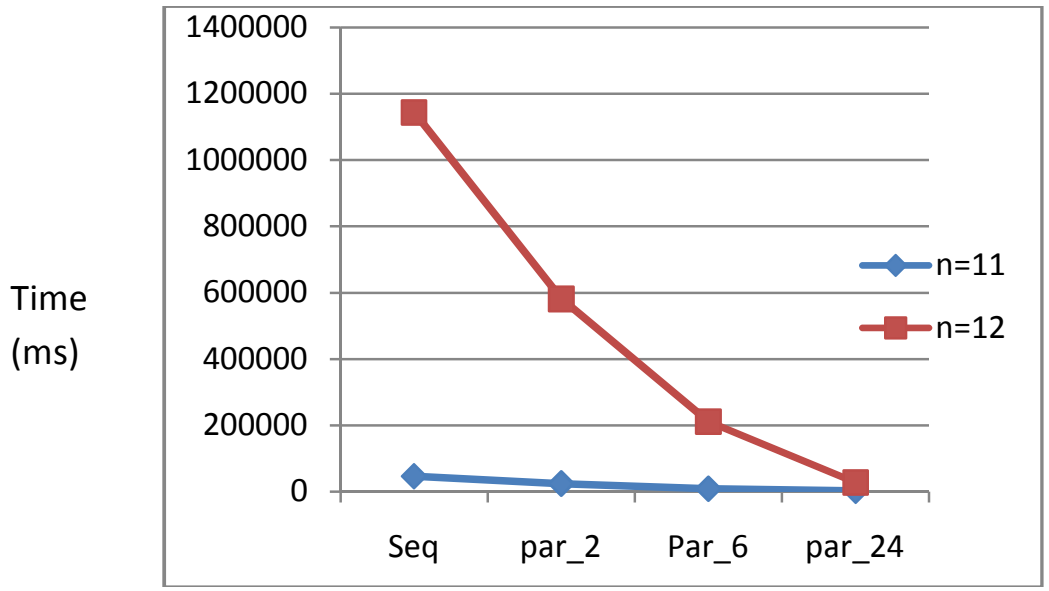

Figure 8 . The graph illustrates time listing permutation of $n=11$ and $n=12$ by the subprocessors

Remarks: a close look at Table 4, Figure 7 and Figure 8 shows that if $\mathrm{n}$ is large enough, the parallel computation time is much lower than the sequential computation time. When the sub processors increase in number, the computation time will decrease. When $\mathrm{n}$ increases to 1 unit, the number of permutations increases dramatically, so the computation time goes up sharply (Figure 8). However, if you abuse and increase too many processors, the computation time will also go up. 
International Journal of Computer Science \& Information Technology (IJCSIT) Vol 10, No 5, October 2018

\section{CONCLUSION}

The paper solves the problem of improved computing performance for two listing binary sequences and listing permutations with sufficiently large $\mathrm{n}$. It is an interesting and innovative idea in case $n$ is large. This newly-built parallel algorithm was experimental with large $n$ and with numerous different sub processors. This paper is devoted to building up a general algorithm for multiple processors. Last but not least, it demonstrates the correctness and experiments in multiprocessing MPI and Thread library.

\section{REFERENCES}

1. Nguyen Dinh Lau, Parallel algorithm list permutations, @ 2017,ISBN: 978-604-67-1009-7, 2324/11/2017, Quy Nhon, Binh Dinh, Vietnam, pp 348-353.

2. Nguyen Dinh Lau, Parallel algorithm for the graph, Doctoral dissertation, University of Technology, The University of Da Nang, 2015.

3. Hoang Chi Thanh, Parallel Generation of Permutations by Inversion Vectors,Proceedings of IEEERIVF International Conference on Computing and Communication Technologies, IEEE, ISBN: 9781-4673-0308-8, 2012, pp.129-132.

4. Hoang Chi Thanh, Parallelizing a new algorithm for the set partition problem, Annals UMCS Information AIX, 2(2010) pp. 21-28, DOI:10.2478/v10065-010-0049-1, 2010, (http://dlibra.umcs.lublin.pl/dlibra/plain-content?id=12053)

5. Hoang Chi Thanh, Nguyen Thi Thuy Loan. Nguyen Duy Ham, From Permutations to Iterative Permutations, International Journal of Computer Science Engineering and Technology, Vol 2, Issue 7, 2012, pp. 1310-1315.

6. Hoang Chi Thanh, Parallel combinatorial algorithms for multi-sets and their applications, International Journal of Software Engineering and Knowledge Engineering, Vol. 23, No. 01, 2013, pp. $81-99$

7. Hoàng Chi Thanh, Inheritance principle and some bounded sequence problems, The Journal of Computer Science and Cybernetics, T.29 S.1, 2013, pp. 79-91.

8. Ivan Stojmenovic, Listing combinatorial objects in parallel, The international journal of parallel emergent and distributed systems, vol. 21, no. 2, April 2006, pp. 127-146.

9. Akl, S.G., Gries, D. and Stojmenovic, I., An optimal parallel algorithm for generating combinations, Information Processing Letters, 33, 1989, pp. 135-139.

10. Akl, S.G., Meijer, H. and Stojmenovi, I., An optimal systolic algorithm for generating permutations in lexicographic order, Journal of Parallel and Distributed Computing, 20(1), 1994, pp. 84-91.

11. Akl, S.G. and Stojmenovic I., Parallel algorithms for generating integer partitions and compositions, The Journal of Combinatorial Mathematics and Combinatorial Computing, 13, 1983, pp. 107-120.

12. Chen, G.H. and Chern, M.S., Parallel generation of permutations and combinations, BIT, 26, 1986, pp. 277-283. 
International Journal of Computer Science \& Information Technology (IJCSIT) Vol 10, No 5, October 2018

13. Cosnard, M. and Ferreira, A.G., Generating permutations on a VLSI suitable linear network, The Computer Journal, 32(6),1989, pp. 571-573.

14. Djokic, B., Miyakawa, M., Sekiguchi, S., Semba, I. and Stojmenovic, I., Parallel algorithms for generating subsets and set partitions. In: T. Asano, T. Ibaraki, H. Imai and T. Nishizeki (Eds.) Proceedings of SIGAL International Symposium on Algorithms, Tokyo, Japan, Lecture Notes in Computer Science, Vol. 450, 1990, pp. 76-85.

15. Even, S., Algorithmic Combinatorics (New York: Macmillan). Er, M.C., 1988, A parallel algorithm for cost-optimal generation of permutations of $r$ out of $n$ items, Journal of Information \& Optimization Sciences, 9, 1973, pp. 53-56.

16. Elhage, H. and Stojmenovic, I., Systolic generation of combinations from arbitrary elements, Parallel Processing Letters, 2(2/3), 1992, pp. 241-248.

17. Gupta, P. and Bhattacharjee, G.P., Parallel generation of permutations, The Computer Journal, 26(2), 1983, pp. 97-105.

18. Kapralski, A., New methods for the generation of permutations, combinations, and other combinatorial objects in parallel, Journal of Parallel and Distributed Computing, 17, 1993, pp. 315326.

19. Seyed H. Roosta, Parallel Processing and Parallel Algorithms, Theory and Computation,USA,Springer 1999.

20. Steve Fortune and James Wyllie, Parallelism in random access machines, STOC '78 Proceedings of the tenth annual ACM symposium on Theory ofcomputing, 1978, pp 114-118.

21. Nguyen Dinh Lau, Tran Quoc Chien, Phan Phu Cuong, Le Hong Dung, On the implementation of Goldberg's maximum Flow Algorithm in extended mixed network, International Journal of computer Science \& Information Technology, Vol 9, No 6 pp. 93-102, 2017.

22. Nguyen Dinh Lau, Tran Quoc Chien,Algorithm to Find Maximum Concurent Multicommodity Linear Flow with Limited Cost on Extended Traffic Network with Single Regulating Coeffitient on Two-Side Lines, The International Journal of Computer Networks \& Communications, V 9 N2, pp: 57-67, 2017.

23. Nguyen Dinh Lau, Tran Quoc Chien,Traveling Salesman Problem in Distributed Envirenment, Computer Sciencs \& Information Technology (CSIT), Fourth International Conference on Advanced Information Technologies and Applications (ICAITA 2015), pp. 19-28, 2015.

24. Peter S. Pacheco, An Introduction to Parallel Programming, Morgan Kaufmann Publishers is an imprint of Elsevier, ISBN 978-0-12-374260-5 (hardback), 2011 